\title{
Cancer risk assessment of selected hazardous air pollutants in Seattle
}

\author{
Chang-fu $\mathrm{Wu}^{\mathrm{a}, \mathrm{b}, *}$, Szu-ying $\mathrm{Wu}^{\mathrm{b}}{ }^{\mathrm{b}}$, Yi-Hua $\mathrm{Wu}^{\mathrm{b}}$, Alison C. Cullen ${ }^{\mathrm{c}}$, Timothy V. Larson ${ }^{\mathrm{d}}$, \\ John Williamson ${ }^{\mathrm{e}}$, L.-J. Sally Liu ${ }^{\mathrm{f}, \mathrm{g}}$ \\ a Department of Public Health, National Taiwan University, Taipei, Taiwan \\ ${ }^{\mathrm{b}}$ Institute of Environmental Health, Institute of Occupational Medicine and Industrial Hygiene, National Taiwan University, Taipei, Taiwan \\ c Evans School of Public Affairs, University of Washington, Seattle, WA, USA \\ ${ }^{\mathrm{d}}$ Department of Civil and Environmental Engineering, University of Washington, Seattle, WA, USA \\ e Air Quality Program, Washington State Department of Ecology, Bellevue, WA, USA \\ ${ }^{\mathrm{f}}$ Department of Environmental and Occupational Health Sciences, University of Washington, Seattle, WA, USA \\ ${ }^{g}$ Institute of Social \& Preventive Medicine, University of Basel, Switzerland
}

\section{A R T I C L E I N F O}

\section{Article history:}

Received 19 June 2008

Accepted 24 September 2008

Available online 8 November 2008

\section{Keywords:}

Risk assessment

Source apportionment

Bootstrapping

Diesel exhaust

Air toxics

\begin{abstract}
A B S T R A C T
The risk estimates calculated from the conventional risk assessment method usually are compound specific and provide limited information for source-specific air quality control. We used a risk apportionment approach, which is a combination of receptor modeling and risk assessment, to estimate source-specific lifetime excess cancer risks of selected hazardous air pollutants. We analyzed the speciated $\mathrm{PM}_{2.5}$ and VOCs data collected at the Beacon Hill in Seattle, WA between 2000 and 2004 with the Multilinear Engine to first quantify source contributions to the mixture of hazardous air pollutants (HAPs) in terms of mass concentrations. The cancer risk from exposure to each source was then calculated as the sum of all available species' cancer risks in the source feature. We also adopted the bootstrapping technique for the uncertainty analysis. The results showed that the overall cancer risk was $6.09 * 10^{-5}$, with the background $\left(1.61 * 10^{-5}\right)$, diesel $\left(9.82 * 10^{-6}\right)$ and wood burning $\left(9.45 * 10^{-6}\right)$ sources being the primary risk sources. The $\mathrm{PM}_{2.5}$ mass concentration contributed $20 \%$ of the total risk. The 5 th percentile of the risk estimates of all sources other than marine and soil were higher than $1 * 10^{-6}$. It was also found that the diesel and wood burning sources presented similar cancer risks although the diesel exhaust contributed less to the $\mathrm{PM}_{2.5}$ mass concentration than the wood burning. This highlights the additional value from such a risk apportionment approach that could be utilized for prioritizing control strategies to reduce the highest population health risks from exposure to HAPs.
\end{abstract}

(c) 2008 Elsevier Ltd. All rights reserved.

\section{Introduction}

In conventional risk assessment studies of air pollutants, the estimated cancer risk, i.e. the additional risk of developing cancer due to continuous lifetime exposures to carcinogenic compounds, is calculated as the product of unit risk and the exposed concentration (USEPA, 2005a). The concentration estimates are usually based on measurements of individual hazardous air pollutants (HAPs) and the risk estimates are compound specific. For example, using measurements at 25 air monitoring sites in Minnesota, Pratt et al. (2000) estimated that the cancer risks of 16 pollutants ranged between $4.7 * 10^{-5}$ and $11.0 * 10^{-5}$. Similarly, Tam and Neumann, (2004), utilizing measurements at five air monitoring sites in Portland, OR, calculated the cancer risks for 43 HAPs. They showed that 17 HAPs exceeded the cancer risk level of $1 * 10^{-6}$ at all sites, with carbon tetrachloride, 1,3-butadiene, formaldehyde, and 1,1,2,2-

\footnotetext{
* Corresponding author. National Taiwan University, Room 717, No.17, Xu-Zhou Rd. Taipei 100, Taiwan. Tel./fax: +88623322 8096.

E-mail address: changfu@ntu.edu.tw (C.-f. Wu).
}

tetrachloroethane contributing $50 \%$ of the total lifetime cancer risks $\left(2.47 * 10^{-4}\right)$.

From the risk reduction viewpoint, compound-specific risk estimates provide limited information for source-specific air quality management, due to contributions of multiple sources to each compound. For example, formaldehyde was identified as one of the main risk contributors in many regions (e.g. Sax et al., 2006; Woodruff et al., 2000). However, in an urban environment it comes from a multitude of sources such as diesel exhaust, wood burning smoke, industrial activities, photochemical products, etc. For developing effective control strategies for sources imposing the highest health risks, source-specific risk estimates would provide more indicative information. The US National Scale Air Toxics Assessment (NATA) study adapted this approach with modeled ambient concentrations as the main inputs for generating source-specific population exposure and risk estimates with regard to major, area, and mobile sources. It was estimated that the national-wide total risk was $4.15^{*} 10^{-5}$ with the greatest contribution from on-road mobile sources (USEPA, 2006). The NATA approach depends largely on emission inventory data and various models without actual measurements. Errors propagating 
along the modeling processes could heavily influence the risk estimates. In addition, these risk estimates were limited to those pre-specified source categories available from the emission inventory (Cook et al., 2007; USEPA, 2006).

An alternative method less constrained by the aforementioned limitations is the risk apportionment approach (Mukerjee and Biswas, 1992), which is a combination of risk assessment and receptor modeling using actual measurements. Receptor models estimate contributions from individual sources in terms of mass concentrations. Mukerjee and Biswas (1992) made the initial demonstration by using the Chemical Mass Balance model to apportion six samples of total suspended particulate matters collected at a receptor site near several industrial sources. The source-specific risks were calculated by summing the species-specific risks for each source profile including paved road dust $\left(7.5^{*} 10^{-5}\right)$, blast furnace $\left(6.8 * 10^{-6}\right)$ and sinter plants $\left(3.4 * 10^{-5}\right)$.

Our previous source apportionment study in Seattle, WA (Wu et al., 2007) estimated that wood burning smoke and secondary sulfate contributed equally to the fine particulate matters $\left(\mathrm{PM}_{2.5}\right.$, aerodynamic particle diameter $<2.5 \mu \mathrm{m}$ ) mass concentrations $(24 \%)$, higher than that from diesel exhaust (10\%). However, the source apportionment results alone do not provide information on health hazards of these sources. In this study, we expanded and improved the risk apportionment approach to estimate source-specific lifetime excessive cancer risks of selected hazardous air pollutants in Seattle, WA. We calculated source-specific concentrations of $\mathrm{PM}_{2.5}$ and volatile organic compounds (VOCs) using the Multilinear Engine (ME) model without a priori source profiles (Paatero, 1999). Cancer risks and the associated uncertainties were further calculated using bootstrapping, with an emphasis on health risks of the diesel particulate matters (DPM).

\section{Materials and methods}

\subsection{Sample collection and source apportionment}

Speciated $\mathrm{PM}_{2.5}$ and VOCs samples were collected at the Beacon Hill monitoring site in Seattle from 2000 to $2004(N=268)$. Beacon Hill is an urban-scale semi-residential site, located within $2 \mathrm{~km}$ of two major interstate freeways and arterial roads, as well as within $4 \mathrm{~km}$ of a warehousing area and a major seaport. It represents average $\mathrm{PM}_{2.5}$ concentrations in a typical Seattle residential neighborhood (Goswami et al., 2002). The $\mathrm{PM}_{2.5}$ samples were collected using the IMPROVE method and analyzed for mass, trace elements, sulfate $\left(\mathrm{SO}_{4}^{2-}\right)$, nitrate $\left(\mathrm{NO}_{3}^{-}\right)$, organic carbon $(\mathrm{OC})$, and elemental carbon (EC). The VOCs, collected using the DNPH cartridge and the SUMA canister (Wu et al., 2007), included formaldehyde, acetaldehyde, Benzene, 1,3-Butadiene, Carbon Tetrachloride, Chloroform, Tetrachloroethylene, and Trichloroethylene. These VOCs were on the list of the top 33 urban HAPs (USEPA, 1999) and were chosen for monitoring due to the expected high concentrations and health risks in the Seattle area.

The source-specific concentrations of each species were calculated in our previous study using the ME model (Wu et al., 2007). In the ME

Table 1

Modeled and measured mass concentrations $\left(\mathrm{ng} / \mathrm{m}^{3}\right)$ of each species

\begin{tabular}{|c|c|c|c|c|c|c|c|c|}
\hline \multirow[t]{2}{*}{ Element } & \multicolumn{4}{|c|}{ Base data } & \multicolumn{3}{|c|}{ Bootstrap } & \multirow{2}{*}{$\begin{array}{l}\text { Unit risk } \\
\left(\text { risk/ng/m } / \mathrm{m}^{3}\right)\end{array}$} \\
\hline & $\mathrm{Abbr}$ & Measured & Modeled & $\operatorname{Diff}(\%)^{\mathrm{a}}$ & $\mathrm{p} 25^{\mathrm{b}}$ & Median & $\mathrm{p} 75^{\mathrm{b}}$ & \\
\hline \multicolumn{9}{|l|}{$\left(P M_{2.5}\right)$} \\
\hline Organic carbon & OC & 2561.9 & 2475.3 & -3.4 & 1443.4 & 2312.8 & 3250.0 & - \\
\hline Elemental carbon & EC & 612.9 & 585.6 & -4.5 & 407.7 & 551.9 & 720.8 & - \\
\hline Ammonium & $\mathrm{NH}_{4}$ & 456.1 & 450.5 & -1.2 & 310.6 & 400.2 & 548.9 & - \\
\hline Arsenic & As & 1.0 & 1.3 & 33.0 & 0.7 & 1.1 & 1.8 & $4.3 \mathrm{E}-06^{\mathrm{c}}$ \\
\hline Bromine & $\mathrm{Br}$ & 2.0 & 2.4 & 19.9 & 1.8 & 2.4 & 3.1 & - \\
\hline Calcium & $\mathrm{Ca}$ & 26.7 & 25.1 & -6.1 & 19.6 & 24.8 & 31.2 & - \\
\hline Chlorine & $\mathrm{Cl}$ & 60.2 & 59.3 & -1.5 & 51.1 & 58.9 & 65.6 & - \\
\hline Chromium & $\mathrm{Cr}$ & 1.6 & 2.3 & 42.5 & 1.3 & 1.9 & 2.7 & $2.4 \mathrm{E}-06^{\mathrm{e}}$ \\
\hline Copper & $\mathrm{Cu}$ & 4.3 & 4.4 & 1.9 & 3.1 & 4.1 & 5.4 & - \\
\hline Iron & $\mathrm{Fe}$ & 51.6 & 49.9 & -3.3 & 30.8 & 45.1 & 63.7 & - \\
\hline Lead & $\mathrm{Pb}$ & 3.7 & 5.2 & 38.6 & 2.7 & 4.7 & 6.9 & $1.2 \mathrm{E}-08^{\mathrm{d}}$ \\
\hline Manganese & $\mathrm{Mn}$ & 3.0 & 3.9 & 30.4 & 2.4 & 3.3 & 4.7 & - \\
\hline Nickel & $\mathrm{Ni}$ & 2.3 & 2.4 & 4.4 & 1.3 & 2.0 & 2.8 & $4.8 \mathrm{E}-07^{\mathrm{f}}$ \\
\hline Nitrate nonvolatile & $\mathrm{NO}_{3}$ & 459.3 & 460.1 & 0.2 & 357.3 & 425.6 & 544.6 & - \\
\hline Potassium ion & $\mathrm{K}$ & 29.5 & 38.5 & 30.6 & 25.1 & 36.5 & 49.1 & - \\
\hline Silicon & $\mathrm{Si}$ & 42.1 & 40.6 & -3.4 & 28.0 & 39.3 & 55.2 & - \\
\hline Sodium ion & $\mathrm{Na}$ & 151.8 & 147.6 & -2.8 & 117.7 & 136.9 & 169.4 & - \\
\hline Sulfate & $\mathrm{SO}_{4}$ & 1191.2 & 1188.9 & -0.2 & 831.5 & 1090.8 & 1446.7 & - \\
\hline Tin & Sn & 5.1 & 7.7 & 51.8 & 4.7 & 7.5 & 10.2 & - \\
\hline Titanium & $\mathrm{Ti}$ & 2.6 & 3.6 & 36.1 & 2.5 & 3.5 & 4.5 & - \\
\hline Vanadium & V & 3.5 & 3.9 & 12.2 & 2.3 & 3.2 & 4.6 & - \\
\hline Zinc & $\mathrm{Zn}$ & 8.8 & 8.3 & -6.1 & 5.5 & 8.0 & 10.8 & - \\
\hline Sum & & 5681.2 & 5566.5 & -2.0 & 3651.0 & 5164.5 & 7002.6 & \\
\hline \multicolumn{9}{|l|}{ (VOCs) } \\
\hline Acetaldehyde & Ace & 1448.4 & 1297.0 & -10.5 & 711.4 & 1171.1 & 1652.1 & $2.2 \mathrm{E}-09^{\mathrm{c}}$ \\
\hline Formaldehyde & For & 1505.8 & 1257.6 & -16.5 & 595.8 & 1116.3 & 1698.1 & $1.3 \mathrm{E}-08^{\mathrm{c}}$ \\
\hline Benzene & Ben & 1329.7 & 1123.6 & -15.5 & 757.4 & 1071.7 & 1443.7 & $7.8 \mathrm{E}-09^{\mathrm{c}}$ \\
\hline 1,3-Butadiene & But & 119.1 & 147.0 & 23.4 & 101.1 & 139.4 & 183.5 & $3.0 \mathrm{E}-08^{\mathrm{c}}$ \\
\hline Chloroform & Chl & 237.8 & 234.6 & -1.4 & 149.5 & 215.9 & 287.1 & $2.3 \mathrm{E}-08^{\mathrm{c}}$ \\
\hline Carbon tetrachloride & Car & 641.2 & 634.9 & -1.0 & 462.4 & 602.4 & 752.8 & $1.5 \mathrm{E}-08^{\mathrm{c}}$ \\
\hline Tetrachloroethylene & Tet & 182.4 & 179.2 & -1.8 & 124.3 & 172.0 & 227.6 & $5.6 \mathrm{E}-09^{\mathrm{d}}$ \\
\hline Trichloroethylene & Tri & 169.2 & 208.0 & 23.0 & 146.8 & 197.2 & 248.2 & $2.0 \mathrm{E}-09^{\mathrm{d}}$ \\
\hline Sum & & 5633.6 & 5081.7 & -9.8 & 3048.7 & 4685.9 & 6493.1 & \\
\hline
\end{tabular}

a Diff $\%=($ modeled concentration - measured concentration $) /$ measured concentration $* 100 \%$.

b p25 and p75 represent the 25th and 75th percentiles calculated from the bootstrapping process.

c Reference from IRIS, website: http://www.epa.gov/iris/index.html.

d Reference from Cal EPA, website: http://www.oehha.ca.gov/air/hot_spots/pdf/May2005Hotspots.pdf.

e Reference from IRIS (assuming that $20 \%$ of all atmospheric chromium is hexavalent).

${ }^{f}$ Reference from IRIS (unit risk for nickel subsulfide). 

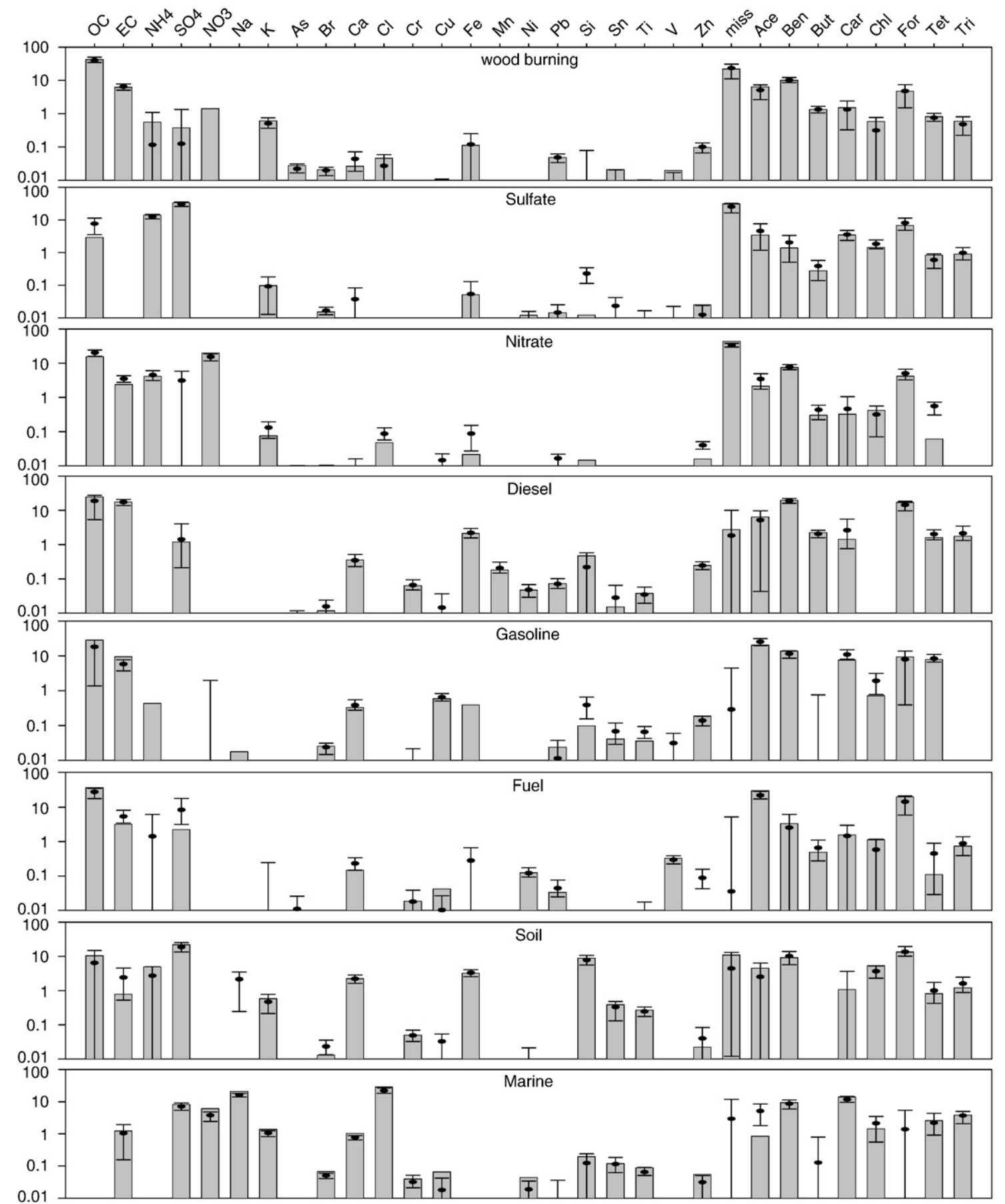

0.01

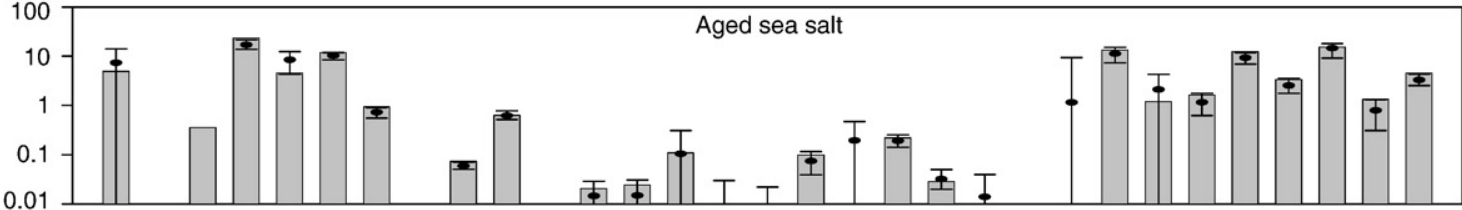

踾

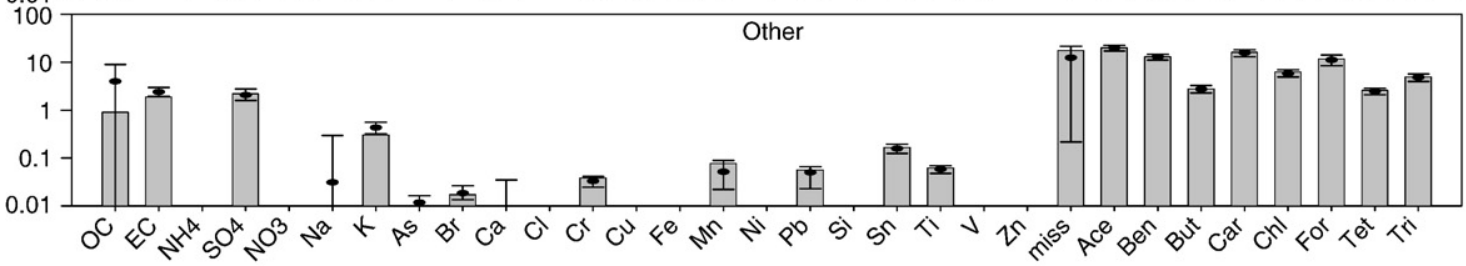

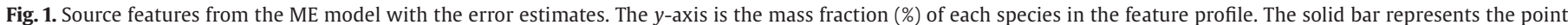

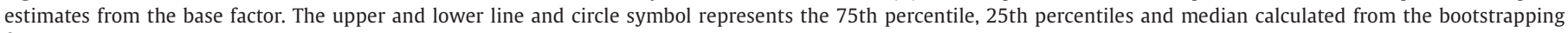
factors. 
model, individual species measured in each air sample is expressed as the sum of contributions from individual sources as below:

$x_{i j}=\sum_{k=1}^{p} f_{j k} g_{k i}+e_{i j}$

where $x_{i j}$ is the $j$ th species concentration measured in the $i$ th sample, $g_{k i}$ is the source contribution defined as the mass concentration from the $k$ th source contributing to the $i$ th sample, $f_{j k}$ is the source feature defined as the $j$ th PM species or VOCs mass fraction from the $k$ th source, $e_{i j}$ is the error term associated with the $j$ th species concentration measured in the $i$ th sample, and $p$ is the total number of independent sources. The main model outputs contain the species composition of each source (i.e. $f_{j k}$ or source features) and the overall contributions of each source (i.e. $g_{k i}$ ). We used the 'missing mass', i.e., the concentration of the measured total particle mass minus the sum of all analyzed species, as an additional variable and implemented an auxiliary equation to constrain the sum of all species mass fractions to be $100 \%$ (Larson et al., 2006; Wu et al., 2007). This 100\% constraint prevents any serious under- or overestimation in the subsequent risk estimates.

Using both $\mathrm{PM}_{2.5}$ and VOCs measurements in the ME model, we identified ten features, including wood burning, secondary sulfate, nitrate, gasoline, diesel, fuel oil, aged sea salt, soil, marine, and the urban background concentration of VOCs (i.e., 'other') (Wu et al., 2007). We found a better model fit for the $\mathrm{PM}_{2.5}\left(R^{2}=0.88\right)$ than for the VOCs $\left(R^{2}=0.72\right)$ portion. The major $\mathrm{PM}_{2.5}$ emission sources included wood burning (24\%), secondary sulfate (24\%) and nitrate (20\%). The majority of the measured vapor phase HAPs came from the general urban background (26\%), wood burning (14\%), and diesel exhaust (14\%).

In this study, we further calculated the mean source specific concentrations of individual HAPs $\left(x_{j k}^{*}\right)$ as follows:

$x_{j k}^{*}=f_{j k} \times \bar{g}_{k}$

where $x_{j k}^{*}$ is the concentration of the $j$ th species from the $k$ th source, $f_{j k}$ is the source feature in Eq. (1), and $\bar{g}_{k}$ is the mean contribution from the $k$ th source.

\subsection{Risk assessment}

With $x_{j k}^{*}$, the cancer risk from exposure to the $k$ th source $\left(R_{k}\right)$ can be calculated as the sum of cancer risks of all available species in its source feature:

$R_{k}=\sum\left(x_{j k}^{*} \times\right.$ Unit Risk $k_{j}$

Unit risk values for each species were taken first from the Integrated Risk Information System (IRIS) (USEPA, 2005b). When the IRIS unit risk of a specific species is not available, the Unit Risk
Estimate (URE) provided by the California Environmental Protection Agency (CalEPA) was used (CalEPA, 2005). Species without any unit risk values were not included in the risk assessment process. The unit risk of chromium was adjusted by multiplying a factor of 0.2 , assuming that approximately $20 \%$ of the ambient airborne chromium was in the toxic hexavalent form (Bell and Hipfner, 1997). The unit risk for nickel was adopted from the unit risk for nickel subsulfide in IRIS, assuming that all the monitored nickel was in the insoluble and carcinogenic form.

\subsection{Uncertainty analysis}

As the uncertainty estimates of source features and source contributions were not provided by the standard ME model, we used the bootstrapping technique (Eforn and Tibshirani, 1993) to obtain the uncertainties. The bootstrapping involves creating multiple sets of subsamples and requires no prior statistical assumptions about the underlying distribution of the dataset. Each set of the subsamples is generated from re-sampling the data with replacement (i.e. any data point could be sampled multiple times or not at all). The bootstrapping process was executed with the SAS statistical software (Version 8.02, SAS Institute Inc., Cary, NC, USA) in this study. To obtain reliable results, 300 sets of different input data were generated with 299 sets of resampled data and one 'base' data without any replacement (Eberly, 2005). Each dataset with 268 samples was analyzed with the ME model, resulting in 299 sets of bootstrapping solutions as well as one set of 'base' solutions. While the physical meaning of each source feature in the base solutions was interpreted individually in Wu et al. (2007), it is not practical to do so for all 299 bootstrapping solutions in this study. Thus, these bootstrapping features were matched or 'mapped' to the base features automatically through correlating the time series of the source contributions in the bootstrapping results to those in the base results. The pair with the highest correlation coefficient was retained, requiring that coefficient to be larger than 0.6 (Eberly, 2005).

\section{Results and discussion}

The measured and modeled concentrations of each species were shown in Table 1. Results shown in the 'Modeled' column represent the reconstructed concentrations estimated from the base data while results in the 'Bootstrap' columns represent the statistics from the 299 sets of reconstructed concentrations through the bootstrap resampling processes. The sums of the $\mathrm{PM}_{2.5}$ and VOCs mass concentrations were underestimated by only $2 \%$ and $10 \%$, respectively. For individual species, the absolute percent difference between the measured and modeled values ranged between 0 and $52 \%$, with the larger differences (i.e. arsenic, chromium, lead, manganese, potassium, tin, and titanium) due mostly to the higher percentages of samples below detection limit $(>20 \%)$ for these species. These biases would propagate into the following risk assessment process. However, the bootstrapping results indicated that the measured concentrations were within the 25th to 75th percentile of the bootstrapping range (Table 1), suggesting that the variation from the ME modeling process was mostly taken into account in this uncertainty analysis.

The source features from the base data and the associated uncertainties calculated from the bootstrapping process are shown in Fig. 1. During the mapping process, most

Table 2

Point estimates of the cancer risk (per million) for each source by the risk apportionment approach

\begin{tabular}{|c|c|c|c|c|c|c|c|c|c|c|c|c|c|c|c|}
\hline Sources & As & $\mathrm{Cr}$ & $\mathrm{Ni}$ & $\mathrm{Pb}$ & Ace & Ben & But & Car & Chl & For & Tet & Tri & Sum PM risk & Sum VOCs risk & Sum risk \\
\hline Other & 0.74 & 1.60 & 0 & 0.01 & 0.76 & 1.76 & 1.43 & 4.19 & 2.49 & 2.63 & 0.25 & 0.17 & 2.36 & 13.7 & 16.1 \\
\hline Diesel & 0.33 & 2.17 & 0.32 & 0.01 & 0.2 & 2.18 & 0.96 & 0.31 & 0 & 3.17 & 0.13 & 0.05 & 2.83 & 6.99 & 9.82 \\
\hline Wood & 3.17 & 0 & 0 & 0.02 & 0.37 & 2.08 & 1.07 & 0.6 & 0.36 & 1.64 & 0.12 & 0.03 & 3.18 & 6.27 & 9.45 \\
\hline Aged & 0.32 & 0.44 & 0.02 & 0.01 & 0.26 & 0.08 & 0.44 & 1.69 & 0.7 & 1.79 & 0.07 & 0.08 & 0.79 & 5.11 & 5.90 \\
\hline Fuel & 0.4 & 0.45 & 0.61 & 0.004 & 0.68 & 0.27 & 0.15 & 0.24 & 0.27 & 2.64 & 0.006 & 0.02 & 1.47 & 4.26 & 5.73 \\
\hline Sulfate & 0.31 & 0 & 0.14 & 0.004 & 0.18 & 0.26 & 0.2 & 1.24 & 0.78 & 2.10 & 0.11 & 0.04 & 0.45 & 4.91 & 5.36 \\
\hline Nitrate & 0.24 & 0.01 & 0 & 0.002 & 0.09 & 1.08 & 0.17 & 0.09 & 0.18 & 1.01 & 0.006 & 0 & 0.25 & 2.63 & 2.87 \\
\hline Gasoline & 0 & 0.1 & 0 & 0.001 & 0.27 & 0.65 & 0 & 0.69 & 0.1 & 0.73 & 0.26 & 0 & 0.1 & 2.70 & 2.80 \\
\hline Soil & 0 & 0.44 & 0 & 0 & 0.04 & 0.26 & 0 & 0.06 & 0.45 & 0.64 & 0.017 & 0.009 & 0.44 & 1.47 & 1.91 \\
\hline Marine & 0.03 & 0.19 & 0.04 & 0 & 0.004 & 0.15 & 0 & 0.41 & 0.07 & 0 & 0.03 & 0.02 & 0.27 & 0.68 & 0.94 \\
\hline Sum & 5.55 & 5.40 & 1.13 & 0.062 & 2.85 & 8.77 & 4.42 & 9.52 & 5.4 & 16.35 & 1 & 0.42 & 12.14 & 48.72 & 60.88 \\
\hline
\end{tabular}


(a) Mass concentration - PM

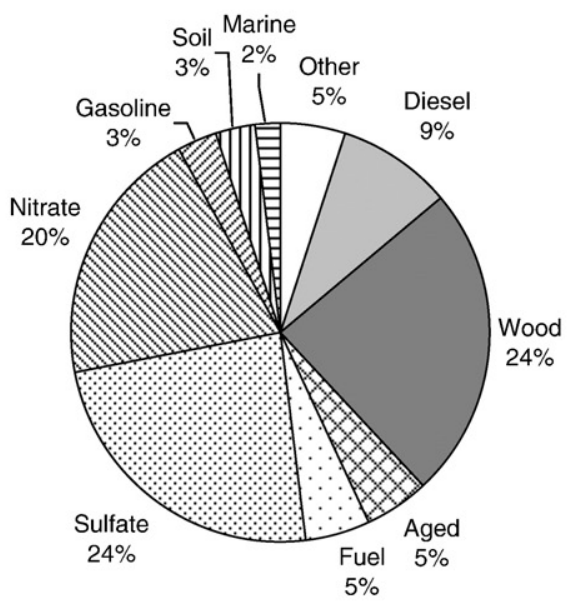

(c) Risk estimates - PM

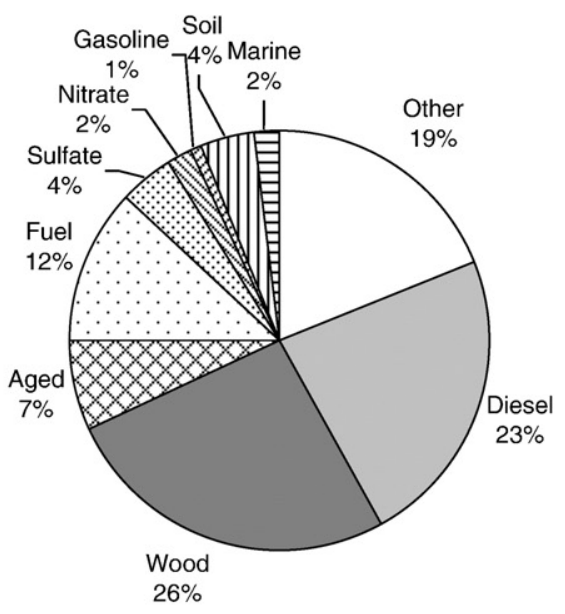

(e) Risk estimates - Sum of PM and VOC

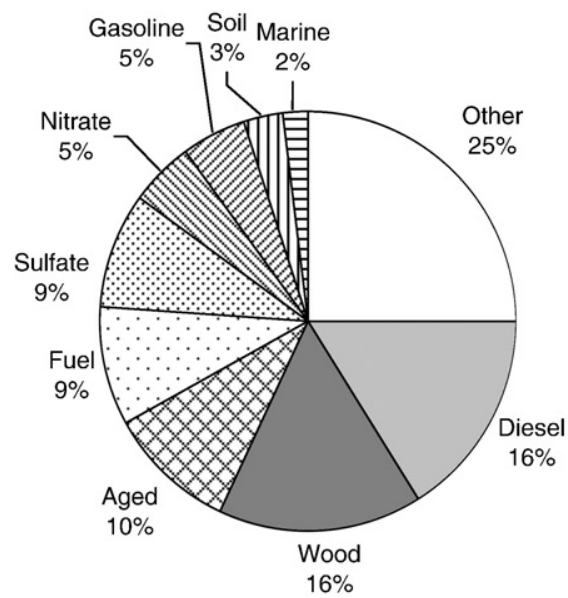

(b) Mass concentration - VOC

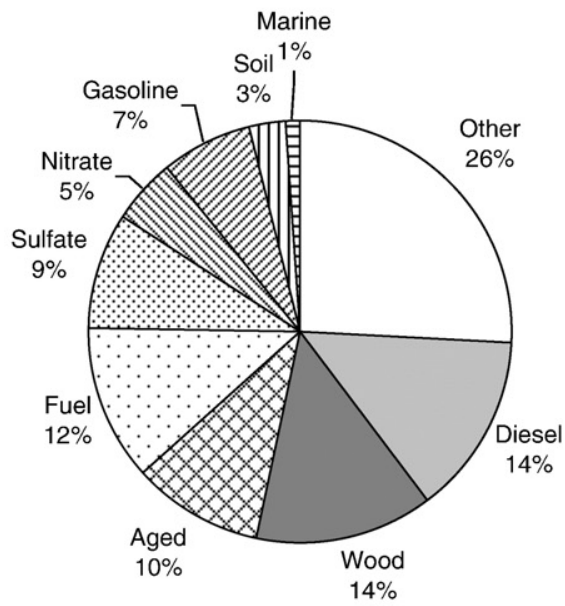

(d) Risk estimates - VOC

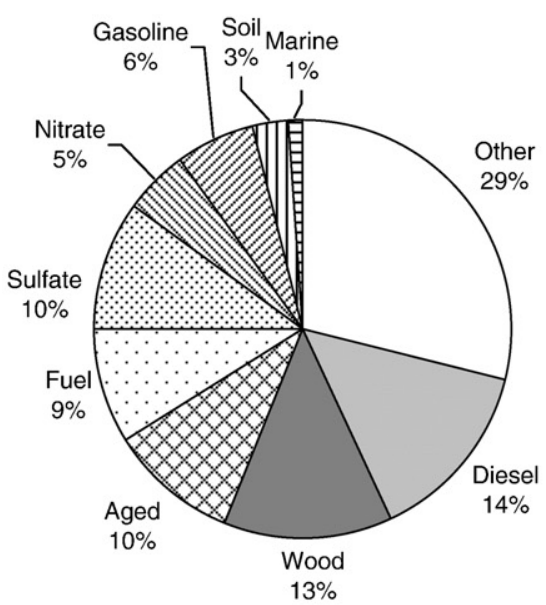

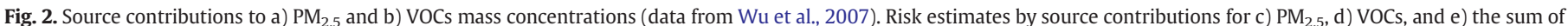
$\mathrm{PM}_{2.5}$ and VOCs.

sources were mapped successfully to one of the base features at least more than 280 times with an $r>0.6$, while soil and 'other' sources were mapped only 220 and 267 times, respectively, implying higher uncertainties for these two source features. Ideally, the range (25th to 75 th percentile) of the error estimates should cover the results from the base data and the median from bootstrapping factor should be close to that from the base data. In this study, although the source features from the base dataset may not always agree well with those from the bootstrapping dataset, good agreement was found for most important marker species that had high contributions in each source 
feature (Fig. 1, e.g. the VOCs fraction in 'other' source; $\mathrm{SO}_{4}$ and $\mathrm{NH}_{4}$ in secondary sulfate source; V and Ni in fuel source; Fe and Mn in diesel source; and the Si and Ca in soil source).

The unit risks were available for $\mathrm{As}, \mathrm{Cr}, \mathrm{Pb}$ and $\mathrm{Ni}$ in the $\mathrm{PM}_{2.5}$ fraction and for all the monitored VOCs (Table 1). The point estimates of excessive cancer risks from the base data were summarized in Table 2 by source and species. The source specific risk values ranged from $1.6 * 10^{-5}$ to $9.4 * 10^{-7}$. All sources except for 'marine' gave a sum of cancer risks higher than $1 * 10^{-6}$. 'Other', diesel and wood burning sources were the primary risk sources in both $\mathrm{PM}_{2.5}$ and VOCs fractions (Fig. 2). The sum of cancer risks were $6.1 * 10^{-5}$, with the $\mathrm{PM}_{2.5}$ portion contributing $20 \%\left(1.2 * 10^{-5}\right)$. Formaldehyde, carbon tetrachloride and benzene posed the highest cancer risks as estimated in other studies (MorelloFrosch et al., 2000; Tam and Neumann, 2004). The overall risk value $\left(11.8 * 10^{-5}\right)$ estimated in the 1999 NATA study at the census tract of the Beacon Hill site was 2 times higher than the overall risk in this study. This is mainly because more species ( 85 species vs. 12 in this study) were simulated in the NATA study. Compared to the risk estimates based on the measured ambient concentrations of 19 species in other cities (Los Angeles, CA: $1.0 * 10^{-4}$; New York City, NY: $1.3 * 10^{-4}$ ), the overall risk in this study was still lower than theirs (Sax et al., 2006).

The main risk contributors to the 'other' source were the VOCs fraction $(13.7 / 16.1 * 100 \%=$ $85 \%$ ) with carbon tetrachloride, formaldehyde and chloroform as the top contributors. The 'other' source from the ME model was considered as the background concentrations of VOCs since the contribution for each VOC was high in the source feature and the reconstructed time series did not show obvious temporal variation (Wu et al., 2007). In the NATA study, the background concentration was defined as components attributable to long-range transport, unidentified emission sources, resuspension of historical emissions, and other natural sources. NATA assigned background concentrations to 29 species (i.e. 27 gaseous HAPs including those 8 VOCs in our study and mercury and diesel PM) on top of the modeled concentrations (USEPA, 2006). The 1999 NATA study estimated a cancer risk of $2.3 * 10^{-5}$ for the background concentrations of HAPs in the Beacon Hill area, which is comparable to our estimate $\left(1.6^{*} 10^{-5}\right)$.

The diesel and wood burning sources presented similar cancer risks (Fig. 2c-d), even though the diesel exhaust contributed less to the $\mathrm{PM}_{2.5}$ mass concentration than the wood burning (Fig. 2a). On the other hand, secondary sulfate, which was mainly formed in southern Washington, along the Canadian border, and in southwestern British Colombia, Canada (Kim et al., 2004), contributed equally to the $\mathrm{PM}_{25}$ mass concentration as wood burning (Fig. 2a) but posed less health risks (Fig. 2c). The above observations highlight the additional information from such a risk apportionment approach that could be utilized for prioritizing control strategies to reduce the highest population health risks from exposure to HAPs.

The uncertainties in risk assessment of each source were shown in Fig. 3, with the point estimates displayed in filled circles. For 'other', sulfate, gasoline and soil sources, the point estimates using the base dataset were close to the median of the distribution, suggesting small uncertainties. Point estimates for fuel, aged sea salt, wood burning and diesel sources were near the higher end of the bootstrapping results, while the point estimates of marine and nitrate were near the lower end. Nevertheless, the 5th percentile of the risk estimates still showed that most sources gave the sum of risks higher than $1 * 10^{-6}$, except for marine and soil.

For risks of DPM, we also utilized the simulated concentrations of DPM from NATA's study and the unit risk $\left(3 * 10^{-4} / \mu \mathrm{g} / \mathrm{m}^{3}\right)$ from CalEPA (2008) to calculate the cancer risk of DPM. The modeled exposure concentrations of DPM from the 1999 NATA study at the Beacon Hill census tract, and within the buffer zones of $1 \mathrm{~km}, 3 \mathrm{~km}$ and $5 \mathrm{~km}$ were 2.17,1.83, 1.63 and $1.55 \mu \mathrm{g} / \mathrm{m}^{3}$, respectively. The apportioned DPM mass concentration in our study was $0.7 \mu \mathrm{g} / \mathrm{m}^{3}$. Multiplying these modeled concentrations by the unit risk of DPM resulted in estimated cancer risks of $6.52 * 10^{-4}, 5.49 * 10^{-4}, 4.9 * 10^{-4}$ and $4.66 * 10^{-4}$, respectively. The DPM risk $\left(2.83 * 10^{-6}\right.$, Table 2$)$ from our risk apportionment approach was 2 orders of

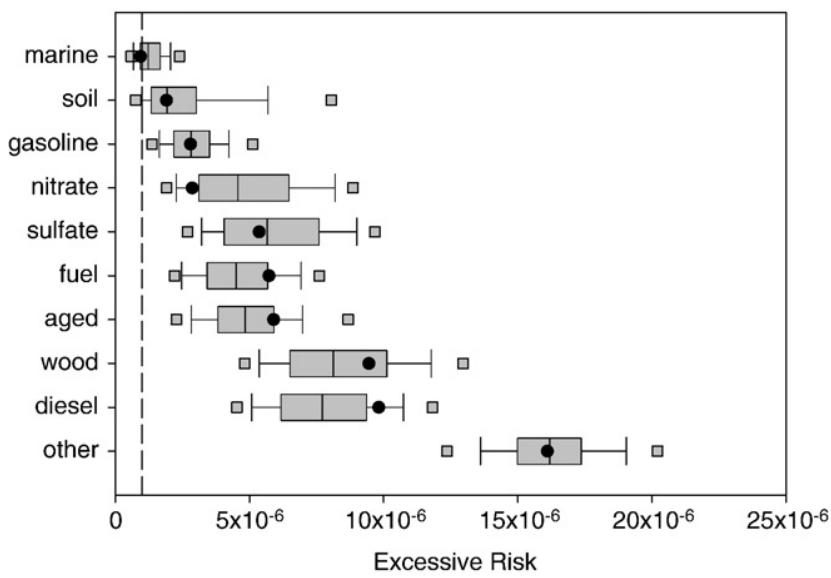

Fig. 3. The risk estimates for each source. The box plot represents the 25th percentile, median, and 75th percentile of the risk estimates. The left and right line represents the 10th and 90th percentiles, and the square symbols represent the 5th and 95th percentiles. The circle symbols represent the risk estimates from the base factors. magnitude lower. This is probably due to our inclusion of only four metal species and no polycyclic aromatic hydrocarbons (PAHs) for DPM in risk calculations. Even after adding risks from the DPM associated VOCs, risk from diesel exhaust was still low $\left(9.82 * 10^{-6}\right)$. On the other hand, the cancer risk estimate $\left(2.09 * 10^{-4}\right)$ calculated using the ME modeled DPM source contributions $\left(0.7 \mu \mathrm{g} / \mathrm{m}^{3}\right)$ and the CalEPA's DPM unit risk was close to those in the NATA study.

The discrepancy for the DPM risk estimates can be attributed to the following reasons. First, the risk apportionment approach tends to underestimate because the results depend on the number of species taken into account. Although 30 species have been analyzed by the ME model in this study, the unit risks are available only for twelve of them. Further, species that are not analyzed cannot be included in the risk calculations. Second, apportioning the diesel exhaust involves considerable uncertainties, as evidenced by the fact that the point estimate of the DPM cancer risks fell outside the 25th and 75th percentile range (Fig. 3). Third, many toxicological studies have showed that the overall chemical reactivity and toxicity of PM or DPM may be greater than the sum of individual components (e.g. Pan et al., 2004). Thus it is likely that the DPM risk estimate based on the sum of risks from individual species is lower than that from using a single 'total' unit risk for DPM. Fourth, the validity of the CalEPA's DPM unit risk itself is still being debated, even though that value is derived from epidemiological data (CalEPA, 2008). The US EPA in its health assessment document concluded that “... human exposure-response data [for diesel exhaust] are considered too uncertain to derive a confident quantitative estimate of cancer unit risk" (USEPA, 2002). Furthermore, many studies did not have adequate quantitative exposure data, did not control for potential confounders, and might not be suitable for newly developed diesel engine technology (Hesterberg et al., 2006).

One major limitation of the risk apportionment approach is that the estimated risk values could be underestimated by the limited set of species considered and the incomplete data of toxicity. The 12 species considered in our study were among the 33 most important urban HAPs based on emissions and toxicities in a 1995 ranking analysis (USEPA, 1999). Other urban HAPs were not monitored because they are considered less stable or lacked approved sampling and analytical methods (PSCAA, 2003). For example, a group of 7 PAHs, which are probable human carcinogens and are used as a surrogate for the much more complex mixture of polycyclic organic matter in the US EPA National Air Toxics Program (USEPA, 1999), are not monitored routinely at the Beacon Hill site. In the 1999 NATA study, naphthalene was estimated to contribute $13.9 \%$ to the total risks, after subtracting the risks from the background concentrations (USEPA, 2005b). Yu et al. (2008) also estimated that the mean cancer risk calculated from 17 species of PAHs in an urban environment was $2.9 * 10^{-4}$. It is possible to include PAHs in the source apportionment models and then calculate their contributions to the estimated cancer risks. One previous source apportionment study identified six sources (i.e. oil, coal, gasoline, diesel, wood, and other) of PAHs in the urban atmosphere (Larsen and Baker, 2003). Another limitation of this study is that the risk estimates pertained to outdoor air at a stationary location. Indoor exposure sources might also have important contributions (Payne-Sturges et al., 2004; Sax et al., 2006).

\section{Conclusions}

The cancer risks associated with the major sources at Beacon Hill were calculated by the risk apportionment approach. These estimated risks were calculated based on the assumption of lifetime exposures to ambient pollutants. They are not actual risk values and are generally regarded as for screening purposes and for preliminary estimation. We further adopted the bootstrapping technique for the uncertainty analysis. The results showed that most of the sources, other than marine and soil, had cancer risks exceeding the acceptable level of $1 * 10^{-6}$. The source with the greatest health concern was the background source which gave a cancer risk of $1.61 * 10^{-5}$ (5th-95th percentile: $1.2 * 10^{-5}$ $2.0 * 10^{-5}$ ), which requires concerted regional efforts to address. The source-specific risks estimated in this study were likely to be underestimated mainly because only a limited number of species was monitored. This is more apparent for the DPM, for which using a single unit risk that is scientifically derived and well examined might be more appropriate for the risk calculation. For the other sources, the risk apportionment approach might be the most feasible method since no source-specific unit risks were developed. Despite the potential underestimation, the estimated risks still exceeded the acceptable level, suggesting that the HAPs in this region are worth further investigation. Our risk apportionment results can provide the guidance for future health risk managers to design the risk reduction strategy more effectively.

\section{Acknowledgements}

This study was conducted as a collaborative effort among the U.S. EPA Region X, the Washington State Department of Ecology (the 
Ecology), the Puget Sound Clean Air Agency, the Washington State University, and the University of Washington. This study was funded by the Ecology under a cooperative agreement with the Washington Cooperative Fish \& Wildlife Research Unit. This study was also partially funded by the U.S. Environmental Protection Agency through its Office of Research and Development under EPA Grant R827355.

\section{References}

Bell RW, Hipfner JC. Airborne hexavalent chromium in southwestern Ontario. J Air Waste Manage Assoc 1997:47:905-10.

CalEPA. Air toxics hot spots program risk assessment guidelines: part II technical support document for describing available cancer potency factors. Office of Environmental Health Hazard Assessment; 2005.

CalEPA. Findings of the scientific review panel on the report on diesel exhaust, http:// www.arb.ca.gov/toxics/dieseltac/de-fnds.htm; accessed June 18, 2008.

Cook R, Strum M, Touma JS, Palma T, Thurman J, Ensley D, et al. Inhalation exposure and risk from mobile source air toxics in future years. J Expo Sci Environ Epidemiol 2007; 17:95-105.

Eberly S. EPA PMF 1.1 user's guide, 27711. Research Triangle Park, NC: US Environmental Protection Agency; 2005.

Eforn B, Tibshirani RJ. An introduction to the bootstrap. London: Chapman and Hall; 1993.

Goswami E, Larson T, Lumley T, Liu LJS. Spatial characteristics of fine particulate matter: identifying representative monitoring locations in Seattle, Washington. J Air Waste Manage Assoc 2002;52:324-33.

Hesterberg T, Bunn WB, Chase GR, Valberg PA, Slavin TJ, Lapin CA, et al. A critical assessment of studies on the carcinogenic potential of diesel exhaust. Crit Rev Toxicol 2006;36:727-76.

Kim E, Hopke PK, Larson TV, Maykut NN, Lewtas J. Factor analysis of Seattle fine particles. Aerosol Sci Technol 2004;38:724-38.

Larsen RK, Baker JE. Source apportionment of polycyclic aromatic hydrocarbons in the urban atmosphere: a comparison of three methods. Environ Sci Technol 2003;37:1873-81.

Larson TV, Covert DS, Kim E, Elleman R, Schreuder AB, Lumley T. Combining size distribution and chemical species measurements into a multivariate receptor model of $\mathrm{PM}_{2.5}$. J Geophys Res - Atmos 2006:111.

Morello-Frosch RA, Woodruff TJ, Axelrad DA, Caldwell JC. Air toxics and health risks in California: the public health implications of outdoor concentrations. Risk Anal 2000;20:273-91.
Mukerjee S, Biswas P. A concept of risk apportionment of air emission sources for risk reduction considerations. Environ Technol 1992;13:635-46.

Paatero P. The multilinear engine - a table-driven, least squares program for solving multilinear problems, including the n-way parallel factor analysis model. J Comput Graph Stat 1999;8:854-88.

Pan CJ, Schmitz DA, Cho AK, Froines J, Fukuto JM. Inherent redox properties of diese exhaust particles: catalysis of the generation of reactive oxygen species by biological reductants. Toxicol Sci 2004:81:225-32.

Payne-Sturges DC, Burke TA, Breysse P, Diener-West M, Buckley TJ. Personal exposure meets risk assessment: a comparison of measured and modeled exposures and risks in an urban community. Environ Health Perspect 2004;112:589-98.

Pratt GC, Palmer K, Wu CY, Oliaei F, Hollerbach C, Fenske MJ. An assessment of air toxics in Minnesota. Environ Health Perspect 2000;108:815-25.

PSCAA. Final report: Puget sound air toxics evaluation. Pudget Sound Clear Air Agency; 2003

Sax SN, Bennett DH, Chillrud SN, Ross J, Kinney PL, Spengler JD. A cancer risk assessment of inner-city teenagers living in New York City and Los Angeles. Environ Health Perspect 2006;114:1558-66.

Tam BN, Neumann CM. A human health assessment of hazardous air pollutants in Portland, OR. J Environ Manag 2004;73:131-45.

USEPA. National air toxics program: the integrated urban strategy. Fed Regist 1999;64 (137):FRL-6376-6377.

USEPA. Health assessment document for diesel engine exhaust. Washington, DC: National Center for Environmental Assessment; 2002.

USEPA. Guidelines for carcinogen risk assessment EPA/630/P-03/001B. Risk assessment forum,. Washington, DC: National Center for Environmental Assessment; 2005a.

USEPA. Integrated risk information system. Available from: <http://www.epa.gov/iris > 2005 b.

USEPA. National-scale air toxics assessment for 1999 Available from: <http://www.epa. gov/ttn/atw/nata1999/>. 2006.

Woodruff TJ, Caldwell J, Cogliano VJ, Axelrad DA. Estimating cancer risk from outdoor concentrations of hazardous air pollutants in 1990. Environ Res 2000;82:194-206.

Wu CF, Larson TV, Wu SY, Williamson J, Westberg HH, Liu LJS. Source apportionment of PM and selected hazardous air pollutants in Seattle. Sci Total Environ 2007;386:42-52.

Yu YJ, Guo HC, Liu Y, Huang K, Wang Z, Zhan XY. Mixed uncertainty analysis of polycyclic aromatic hydrocarbon inhalation and risk assessment in ambient air of Beijing. J Environ Sci (China) 2008;20:505-12. 